\title{
Relevance and clinicopathologic relationship of BRAF V600E, TERT and NRAS mutations for papillary thyroid carcinoma patients in Northwest China
}

Meiling Huang ${ }^{\dagger}$, Changjiao Yan ${ }^{\dagger}$, Jingjing Xiao, Ting Wang ${ }^{*}$ and Rui Ling*

\begin{abstract}
Background: To determine the relevance of the single or combination mutations of BRAF V600E, TERT, and NRAS genes and the clinicopathologic relationship in papillary thyroid cancer (PTC).

Methods: Patients with PTC were enrolled into the study between February 2018 and April 2019. Based on the number of mutant genes, we classified the participants into single BRAF V600E mutation group, double mutations group and no mutation group. Single factor and multiple logistic regression analyses were applied to explore the independent factors. Review Manager 5.3 was used for meta-analysis to review the clinical efficacy of gene co-mutations.

Results: Finally, 483 patients were enrolled into the study and 419 (86.7\%) of them harbored BRAF V600E mutation. TERT or NRAS mutation was likely to coexist with BRAF V600E mutation in PTC. BRAF V600E and NRAS promoter co-mutations was identified in 6 patients, with a prevalence of 1.2\%. Prevalence of BRAF V600E and TERT coexistence in PTC was 2.1\%. Significant differences were found among age, pathology, multifocality, bilateral lesions, lymph node metastasis, and 1311 radiotherapy, $P<0.01$. Multiple logistic regression analyses demonstrated that age [odds ratio $(\mathrm{OR})=1.044,95 \%$ confidence interval $(C l)=1.013-1.076 ; P=0.006]$, lymph node metastasis $[O R=0.094,95 \% C l=0.034-0.264 ; P<0.001]$, 131 l radiotherapy $[\mathrm{OR}=7.628,95 \% \mathrm{Cl}=2.721-21.378 ; P<0.001]$ were risk factors for BRAF V600E mutation. Besides, age $[\mathrm{OR}=$ $1.135,95 \% C l=1.069-1.205 ; P<0.001]$, multiple leisions $[O R=4.128,95 \% C l=1.026-16.614 ; P=0.046]$, pathology $[O R=$ $3.954,95 \% \mathrm{Cl}=1.235-12.654 ; P=0.021]$ were independent factors for combination mutations. Meta-analysis showed significant association of BRAF V600E+/TERT+ co-mutations with lymph node metastasis, multifocality, distant metastasis, tumor recurrence, extrathyroidal extension, and dead of disease.

Conclusions: Prevalence of BRAF V600E mutation in Northwest China was higher than other areas. Age, multiple lesions, and pathology were independent factors for double mutation of BRAF V600E/TERT or BRAF V600E/NRAS. Coexistence of BRAF V600E and TERT promoter mutations was significantly correlated with poor outcome.
\end{abstract}

Keywords: BRAF V600E mutation, TERT mutation, NRAS mutation, Co-mutations, Papillary thyroid carcinoma

\footnotetext{
*Correspondence: lingruiaoxue@126.com; wangting0202@126.com

${ }^{+}$Meiling Huang and Changjiao Yan contributed equally to this work.

Department of Thyroid, Breast, and Vascular Surgery, Xijing Hospital, The

Fourth Military Medical University, Xi'an 710032, China
}

C The Author(s). 2019 Open Access This article is distributed under the terms of the Creative Commons Attribution 4.0 International License (http://creativecommons.org/licenses/by/4.0/), which permits unrestricted use, distribution, and reproduction in any medium, provided you give appropriate credit to the original author(s) and the source, provide a link to the Creative Commons license, and indicate if changes were made. The Creative Commons Public Domain Dedication waiver (http://creativecommons.org/publicdomain/zero/1.0/) applies to the data made available in this article, unless otherwise stated. 


\section{Introduction}

Thyroid cancer is the most common endocrine malignancy, and its global incidence has rapidly increased in recent decades [1]. Papillary thyroid carcinoma (PTC), which is derived from the follicular epithelium, represents 80 to $85 \%$ of thyroid malignancies. Although PTC is highly curable in general, approximately $10 \%$ of patients are destined as progressive disease [2]. Thus, the molecular-based risk stratification has been emphasized to compare treatment-associated benefits. Recently, improved understanding of the molecular pathogenesis and the identification of molecular markers are of high clinical significance, indicating the diagnosis and prognosis of PTC.

Molecular markers have been focused so far, such as BRAF V600E, telomerase reverse transcriptase (TERT) and NRAS, which might be potential prognostic factors for FTC. BRAF V600E mutation was correlated with more aggressive and iodine-resistant phenotypes, providing valuable prognostic information for thyroid cancer [3]. Similarly, TERT promoter mutation was associated with aggressive thyroid tumor characteristics, tumor recurrence, and patient mortality [4]. NRAS gene, the most frequent mutant gene of the RAS gene family, was related to increased risk of distant metastasis $[5,6]$. However, features of gene mutation from different regions are different. In Australian urban population, 68\% of PTC patients were identified with BRAF V600E mutation [7]. In Middle Eastern, TERT promoter mutation was harbored in 6.5\% PTC patients [8]. For PTC patients from Greek, low prevalence of TERT promoter (3.4\%), BRAF V600E (17\%), and RAS mutations (3.4\%) was detected [9]. In China, data of gene mutation for PTC was relatively limited. In 2018, Liang J et al. reported $72.4 \%$ of BRAF V600E mutation and $2.8 \%$ of RAS mutation among 355 Chinese PTC patients [10]. In China, it is essential to achieve more evidence of genetic events as trustworthy prognostic markers for risk stratification and patient management.

Considering the synergistic effects of mutant genes, coexistence of gene mutation should be emphasized. BRAF V600E promoter mutation, in combination with TERT or RAS mutation, was recognized as clinically important diagnostic and prognostic genetic markers for thyroid cancer. TERT, a predominant determinant for controlling the activity of telomerase, was likely to coexist with BRAF V600E mutation in thyroid cancer [11]. In 2016, Sun J et al. found that $94.7 \%$ PTC patients with TERT promoter mutation were detected with BRAF V600E mutation [12]. In 2017, Vuong HG et al. claimed that the combination of BRAF V600E and TERT promoter mutations indicated increasing risk of aggressiveness of PTC than TERT or BRAF V600E mutation alone [13]. In this study, we focused on the prevalence of
BRAF V600E, TERT and NRAS mutations and their association with clinicopathological features in PTC patients from Northwest China.

\section{Materials and methods \\ Participants}

This retrospective study included 483 patients (127 men and 356 women) admitted to Xijing Hospital, between February 2018 and April 2019. The fundamental features were shown in Table 1. All patients underwent preoperative ultrasound and fine-needle aspiration biopsy tests. Total or near-total thyroidectomy, cervical lymph node dissection, and radioiodine therapy were pursued as clinically determined. Pathological diagnosis was established following the World Health Organization criteria and confirmed by expert thyroid cancer pathologists. All patients provided written informed consent. Ethical approval for the study was provided by the Ethical Committees of Xijing Hospital.

\section{Genomic DNA isolation}

Formalin-fixed and paraffin-embedded (FFPE) tumor tissue was achieved for human genomic DNA isolation, using the AmoyDx ${ }^{\circ}$ FFPE DNA Kit (Amoy Diagnostics Co., Ltd., Xiamen, China). Selection of the most representative areas was made by an experienced thyroid pathologist. Before DNA isolation, paraffin was removed

\section{Table 1 Baseline characteristics}

\begin{tabular}{ll}
\hline Index & Data $(\mathrm{N}=483)$ \\
\hline Sex & $127(26.3 \%)$ \\
Female & $356(73.7 \%)$ \\
Age & \\
Average age & $43.15 \pm 11.25$ \\
Median age & $43(14-79)$ \\
Pathology & \\
PTC & $187(38.7 \%)$ \\
PTMC & $296(61.3 \%)$ \\
Lesion number & \\
Single lesion & $342(70.8 \%)$ \\
Multiple lesions & $141(29.2 \%)$ \\
Lesion location & \\
Unilateral & $404(83.6 \%)$ \\
Bilateral & $79(16.4 \%)$ \\
Gene mutation & \\
BRAF V600E mutation alone & $419(86.7 \%)$ \\
BRAF V600E/TERT co-mutation & $10(2.1 \%)$ \\
BRAF V600E/NRAS co-mutation & $6(1.2 \%)$ \\
No mutations in BRAF V600E/TERT/NRAS & $48(9.9 \%)$ \\
\hline
\end{tabular}


by xylene-ethanol extraction, and lysed overnight with $20 \mu \mathrm{L}$ proteinase $\mathrm{K}$ in a $56^{\circ} \mathrm{C}$ rotating incubator. DNA purification was performed using the QIAamp DNA Mini Kit (Qiagen GmBH, Hilden, Germany), according to the manufacturer's instructions. The yielded DNA with sufficient quantity and quality was stored at $-40^{\circ} \mathrm{C}$.

\section{Detection of the BRAF V600E mutation}

BRAF V600E mutation was determined by polymerase chain reaction (PCR) assay. The gene was performed in a final volume of $50 \mu \mathrm{l}$ using as template $100-300 \mathrm{ng}$ of genomic DNA, with $1 \times$ buffer including $1.5 \mathrm{mM} \mathrm{MgCl}_{2}$, $0.2 \mathrm{mM}$ dNTPs, 25 pmoles of each (Forward, Reverse) primer and 1 unit of Taq polymerase (Kapa Biosystems). PCR was run with a step-down protocol: $95^{\circ} \mathrm{C}$ for 5 min $\times 1$ cycle, $95^{\circ} \mathrm{C}$ for $25 \mathrm{~s}, 64^{\circ} \mathrm{C}$ for $20 \mathrm{~s}$, and $72^{\circ} \mathrm{C}$ for $20 \mathrm{~s} \times 15$ cycles; $93^{\circ} \mathrm{C}$ for $25 \mathrm{~s}, 60^{\circ} \mathrm{C}$ for $35 \mathrm{~s}$, and $72{ }^{\circ} \mathrm{C}$ for $20 \mathrm{~s} \times 31$ cycles. DNA sequence was read on $\mathrm{ABI}$ PRISM 3700 DNA Analyzer (Applied Biosystems). PCR efficiency was assessed according to the $\mathrm{Ct}$ value of FAM signal. BRAF V600E was regarded as positive when Ct value lowered than 28 .

\section{Detection of the TERT mutations}

TERT promoter C228T and C250T mutations were identified on genomic tumor DNA using standard PCR. Briefly, a 235-bp region of TERT promoter, containing the hotspots of $\mathrm{C} 228 \mathrm{~T}$ and $\mathrm{C} 250 \mathrm{~T}$ mutations, was PCRamplified using primers 5'-AGTGGATTCGCGGGCACAGA-3' (sense) and 5' -CAGCGCTGCCTGAAACTC$3^{\prime}$ (antisense). The thermal cycling conditions were as follows: $95^{\circ} \mathrm{C}$ for $5 \mathrm{~min} \times 1$ cycle, $95^{\circ} \mathrm{C}$ for $25 \mathrm{~s}, 64^{\circ} \mathrm{C}$ for $20 \mathrm{~s}$, and $72{ }^{\circ} \mathrm{C}$ for $20 \mathrm{~s} \times 15$ cycles; $93^{\circ} \mathrm{C}$ for $25 \mathrm{~s}, 60^{\circ} \mathrm{C}$ for $35 \mathrm{~s}$, and $72{ }^{\circ} \mathrm{C}$ for $20 \mathrm{~s} \times 31$ cycles. After quality confirmation by agarose gel electrophoresis, PCR products were subjected to Sanger sequencing using ABI3500xl Dx Genetic Analyzer (Thermo Fisher, USA). When mutation was identified, an independent PCR amplification/sequencing, both in forward and reverse directions, was performed to confirm the result.

\section{Detection of NRAS mutation by real-time PCR}

When genomic DNA isolation was finished, the detection of NRAS mutation in exon 2 4 was performed by AmoyDx ${ }^{\circ}$ NRAS Mutation Detection Kit (Amoy Diagnostics, Xiamen, China). DNA ( $5 \mu \mathrm{L})$ was added to $35 \mu \mathrm{L}$ PCR master mix, which contained PCR primers, fluorescent probes, PCR buffer, and DNA polymerase. The PCR cycling conditions were: $5 \mathrm{~min}$ denaturation at $95^{\circ} \mathrm{C}$, followed by 15 cycles of $95^{\circ} \mathrm{C}$ for $25 \mathrm{~s}, 64^{\circ} \mathrm{C}$ for $20 \mathrm{~s}, 72^{\circ} \mathrm{C}$ for $20 \mathrm{~s}, 31 \mathrm{cycles}$ of $93^{\circ} \mathrm{C}$ for $25 \mathrm{~s}, 60^{\circ} \mathrm{C}$ for $35 \mathrm{~s}$, and $72{ }^{\circ} \mathrm{C}$ for $20 \mathrm{~s}$. The PCR experiment was performed on ABI 7500 real-time instrument (Life Technologies, Carlsbad, CA, USA). Fluorescent signal was collected from FAM and HEX channels. NRAS mutation assay was determined according to the FAM Ct value.

\section{Statistical analysis}

Quantitative data were expressed as means $( \pm \mathrm{SD})$ for normally distributed variables or as medians and percentiles for non-normally distributed variables. The $t$-test was applied for variables that were normally distributed. Categorical variables were compared using $X^{2}$ tests. All $P$ values were 2 -sided and $P$ less than 0.05 was considered significant. Analyses were performed using SPSS version 22.0 (SPSS Inc., Chicago, IL) and GraphPad Prism version 5 (GraphPad Software Inc., San Diego, USA). Review Manager 5.3 (Cochrane Collaborative, Oxford, UK) was used for meta-analysis.

\section{Results}

\section{BRAF V600E gene mutation alone}

As shown in Fig. 1, 435 (90.1\%) patients with PTC harbored BRAF V600E mutation, including 419 patients with BRAF V600E mutation alone and 16 patients with double mutations. Interestingly, TERT and NRAS mutations were likely to coexist with BRAF V600E mutation in PTC. BRAF V600E and NRAS promoter double mutations were identified in 6 patients, with a prevalence of $1.2 \%$. The mutant site of NRAS gene referred Exon2 G12D/G12S, Exon2 G12X/G13X and Exon3 Q61X. The average $\mathrm{Ct}$ value of NRAS gene was $24.23 \pm 1.379$. Meanwhile, we identified $10(2.1 \%)$ cases of patients with TERT and BRAF V600E co-mutations, the most common mutant site of which was TERT C228T.

\section{Combined mutation of BRAF V600E with TERT or NRAS}

Here we screened 16 (3.3\%) patients with double mutations. Among them, 14/16 (87.5\%) were female. The average age and BMI were $56.0 \pm 11.0$ and $25.38 \pm 2.06$, respectively. Other clinical characteristics were listed in Table 2. It seems like that PTCs with concurrent promoter mutations were associated with increased tumor aggressiveness. A majority of patients with double mutations possessed multiple lesions, metastatic lymph nodes, and achieved total thyroidectomy surgery.

Compared the thyroid function before and after surgery $(2.45 \pm 1.2$ months $)$ of these 16 patients, the TSH $[3.03 \pm 1.65(\mathrm{uIU} / \mathrm{mL})$ vs $19.77 \pm 39.7$ (uIU/mL), $F=17.328$, $P<0.01], \quad$ T4 $\quad[109.86 \pm 12.45(\mathrm{nmol} / \mathrm{L}) \quad$ vs $108.98 \pm 53.94$ $(\mathrm{nmol} / \mathrm{L}), F=9.410, P=0.005]$, FT4 $[16.77 \pm 2.05(\mathrm{pmol} / \mathrm{L})$ vs $20.01 \pm 9.26(\mathrm{pmol} / \mathrm{L}), \quad F=11.389, \quad P=0.003], \quad$ FT3 $[4.63 \pm 0.51(\mathrm{pmol} / \mathrm{L})$ vs $4.28 \pm 1.68(\mathrm{pmol} / \mathrm{L}), F=8.108$, $P=0.009]$, Tg value $[68.37 \pm 137.06(\mathrm{ng} / \mathrm{mL})$ vs $1.25 \pm 2.50$ (ng/mL), $F=7.921, P=0.01]$ were significantly different. The PTH $[61.88 \pm 31.5(\mathrm{pg} / \mathrm{mL})$ vs $48.8 \pm 38.7(\mathrm{pg} / \mathrm{mL})$, $F=0.099, P=0.76]$, T3 $[1.97 \pm 0.23(\mathrm{nmol} / \mathrm{L})$ vs $1.51 \pm 0.61$ $(\mathrm{nmol} / \mathrm{L}), \quad F=3.432, \quad P=0.076], \quad$ TPO $[54.01 \pm 78.59$ 


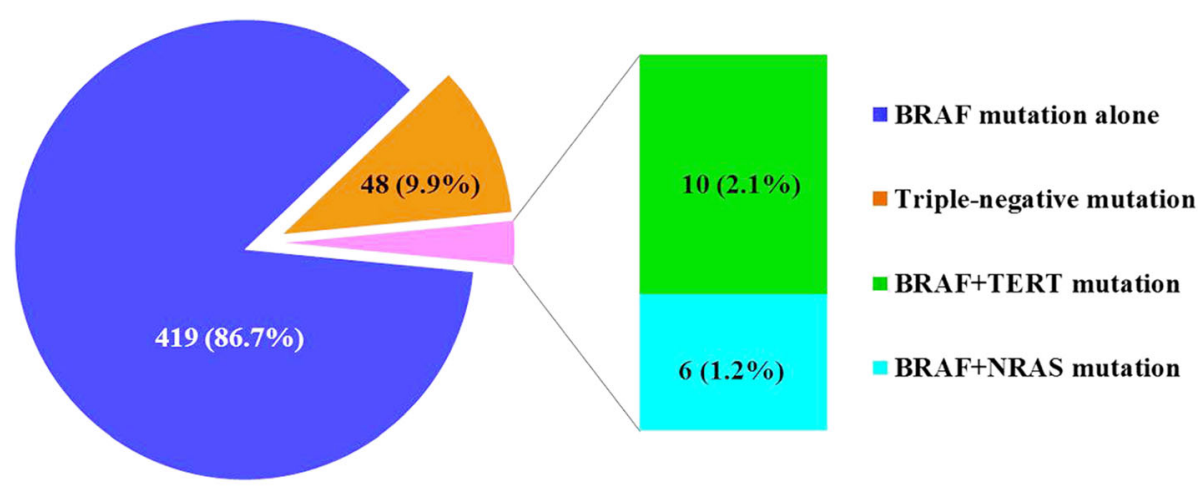

Notes:

Triple-negative mutation: no mutation in BRAF, TERT and NRAS genes

BRAF+TERT mutation: co-mutation in BRAF and TERT genes

BRAF+NRAS mutation: co-mutation in BRAF and NRAS genes

Fig. 1 Distribution of BRAF V600E, TERT, NRAS mutations

$(\mathrm{U} / \mathrm{mL})$ vs $54.08 \pm 61.16(\mathrm{U} / \mathrm{mL}), F=0.129, P=0.722]$, Atg $[719.96 \pm 1175.4(\mathrm{U} / \mathrm{mL})$ vs $521.70 \pm 778.51(\mathrm{U} / \mathrm{mL})$, $F=0.692, P=0.414]$ remained relatively stable. So far, no recurrence, metastasis and mortality were observed.

\section{Relationship of gene mutations with clinicopathological outcomes of PTC}

The risk factors for different gene mutations were explored. As Table 3 indicated, age $(F=16.704, P<0.001)$, pathology $\left(X^{2}=6.207, P=0.045\right)$, number of lesions $\left(\chi^{2}=7.169, P=0.028\right)$, location of lesion $\left(\chi^{2}=8.988, P=0.011\right)$, lymph node metastasis $\left(\chi^{2}=9.983, P=0.007\right)$, and radiotherapy achievement $\left(\chi^{2}=7.463, P=0.024\right)$ were significantly different between 3 groups.

Multiple logistic regression analyses demonstrated that age [odds ratio $(\mathrm{OR})=1.044,95 \%$ confidence interval $(C I)=1.013-1.076 ; P=0.006]$, lymph node metastasis $[\mathrm{OR}=0.094,95 \% C I=0.034-0.264 ; P<0.001]$, and ${ }^{131} \mathrm{I}$ radiotherapy $[\mathrm{OR}=7.628,95 \% C I=2.721-21.378 ; P<0.001$ ] were significantly different between patients with or without BRAF V600E mutation (Table 4). For double mutant group, age $[\mathrm{OR}=1.135,95 \% C I=1.069-1.205 ; P<0.001]$, number of lesion (multiple/single) $[\mathrm{OR}=4.128,95 \%$ $C I=1.026-16.614 ; P=0.046]$, and pathology (PTC/PTMC) $[\mathrm{OR}=3.954,95 \% C I=1.235-12.654 ; P=0.021]$ were independent factors (Table 5).

\section{Literature review of co-existence of BRAF V600E and TERT promoter mutations}

Systematic review was conducted to explore the impact of double gene mutations on clinicopathological features. Fifteen studies with 5057 participants, from inception to October 2018 were included [9, 12, 14-26]. Statistically meaningful association was found between BRAF V600E /TERT promoter co-mutations and lymph node metastasis $(\mathrm{OR}=2.24,95 \% C I=1.53-3.29, P<0.01$, $I^{2}=8 \%$, Fig. 2a), multifocality $(\mathrm{OR}=1.52,95 \% C I=1.07-2.16$, $P=0.02, I^{2}=57 \%$, Fig. $\left.2 \mathrm{~b}\right)$, dead of disease $(\mathrm{OR}=12.63$, 95\%CI =6.85-23.27, $P<0.01, I^{2}=22 \%$, Fig. 2c), distant metastasis $\left(\mathrm{OR}=10.17,95 \% C I=5.39-19.22, P<0.01, I^{2}=39 \%\right.$, Fig. 3a), tumor recurrence $(\mathrm{OR}=8.20,95 \% C I=4.97-13.54$, $P<0.01, I^{2}=66 \%$, Fig. 3b), and extrathyroidal extension $\left(\mathrm{OR}=5.02,95 \% C I=3.32-7.59, P<0.01, I^{2}=0 \%\right.$, Fig. 3c). Vascular invasion $(\mathrm{OR}=1.18,95 \% C I=0.61-2.28, P=0.61$, $I^{2}=47 \%$, Fig. 3d) was found without relationship with mutation coexistence.

\section{Discussion}

In recent decades, the incidence of thyroid cancer has increased significantly, raising an imperative need to explore its pathogenesis, diagnosis, and treatment [27]. Genetic abnormalities maybe crucial in the tumorigenesis of thyroid cancer. Many molecule therapeutics, such as BRAF, has already undergone clinical trials, indicating the need to discover other markers for diagnosis and treatment prediction [28]. So far, the coexistence of gene mutation was focused. In 2014, Xing MZ et al. claimed firstly that the coexisting of BRAF V600E and TERT C228T mutations present the worst clinicopathologic outcomes [26]. Therefore, exploring the function of genetic events as prognostic markers for risk stratification and patient management is essential.

BRAF V600E mutation is the most frequent molecular alteration detected in PTC. But the mutation rate varies around the world. In 2015, Yip L et al. found the most common mutations were BRAF V600E (644/1039, 62\%) in thyroid cancer patients from USA [29]. Identically, $62 \%$ BRAF V600E mutation was detected in Australia [30]. For Argentinean, 77\% of patients operated for PTC harbored BRAF V600E mutation [31]. In 2017, Lee SE 


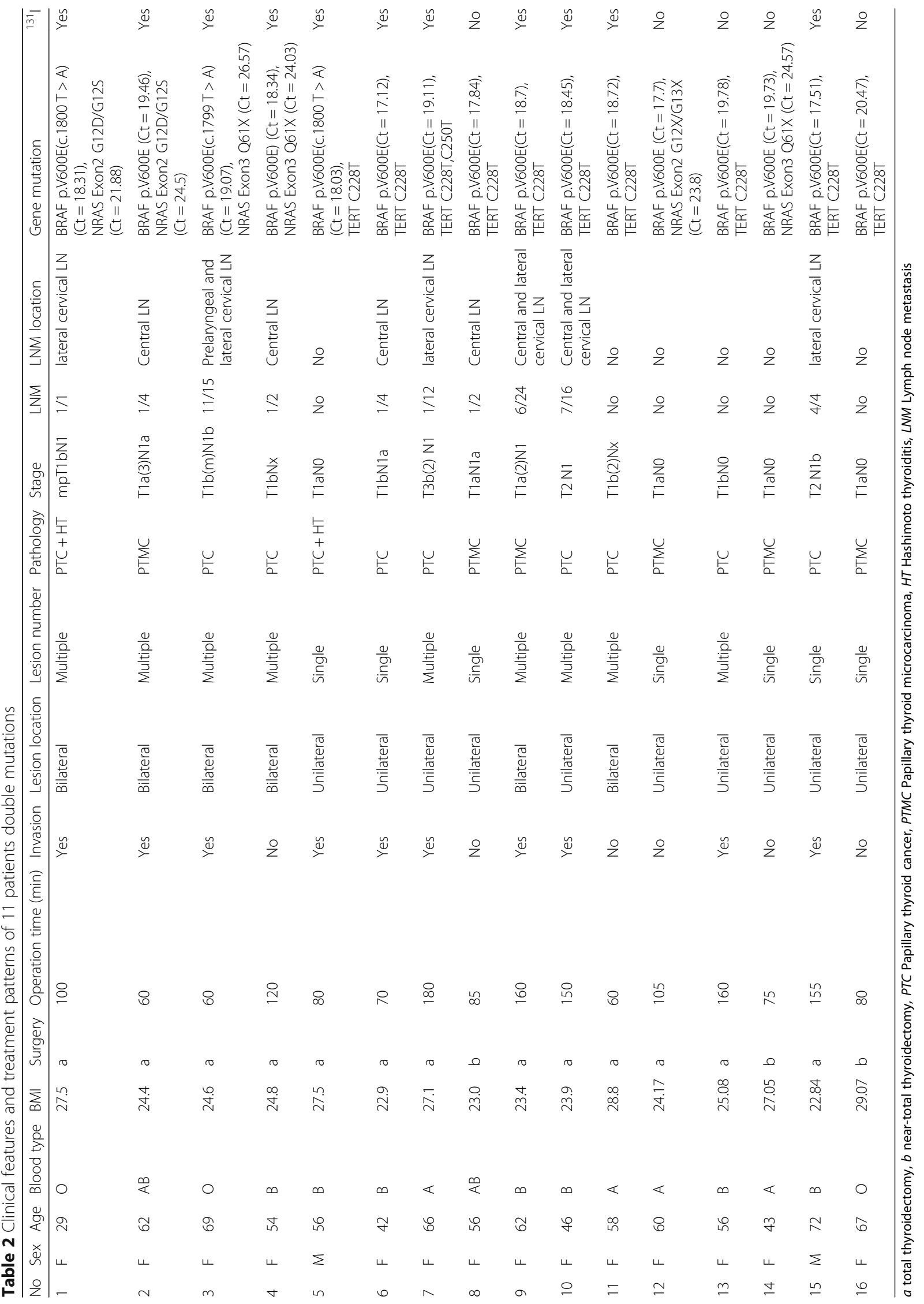


Table 3 Relationship between gene mutations and clinicopathologic features of PTC

\begin{tabular}{|c|c|c|c|c|c|}
\hline & $\begin{array}{l}\text { No gene mutation } \\
(N=48)\end{array}$ & BRAF V600E mutation alone $(N=419)$ & $\begin{array}{l}\text { Double mutations } \\
(N=16)\end{array}$ & $x^{2} / F$ & $P$ \\
\hline \multicolumn{6}{|l|}{ Sex } \\
\hline Male & $13(27.1 \%)$ & $112(26.7 \%)$ & $2(12.5 \%)$ & \multirow[t]{2}{*}{1.627} & \multirow[t]{2}{*}{0.443} \\
\hline Female & $35(72.9 \%)$ & $307(73.3 \%)$ & $14(87.5 \%)$ & & \\
\hline Average age & $37.9 \pm 12.6$ & $43.2 \pm 10.7$ & $56.0 \pm 11.0$ & 16.704 & $<0.001$ \\
\hline Average BMI & $22.8 \pm 3.57$ & $24.9 \pm 5.08$ & $25.38 \pm 2.06$ & 3.521 & 0.316 \\
\hline \multicolumn{6}{|l|}{ Pathology } \\
\hline PTC & $23(47.9 \%)$ & $154(36.8 \%)$ & $10(62.5 \%)$ & \multirow[t]{2}{*}{6.207} & \multirow[t]{2}{*}{0.045} \\
\hline PTMC & $25(52.1 \%)$ & $265(63.2 \%)$ & $6(37.5 \%)$ & & \\
\hline \multicolumn{6}{|l|}{ Lesion number } \\
\hline Single lesion & 38 (79.2\%) & 293(69.9\%) & $7(43.8 \%)$ & \multirow[t]{2}{*}{7.169} & \multirow[t]{2}{*}{0.028} \\
\hline Multiple lesions & $10(20.8 \%)$ & $126(30.1 \%)$ & $9(56.2 \%)$ & & \\
\hline \multicolumn{6}{|l|}{ Lesion location } \\
\hline Unilateral & $38(79.2 \%)$ & $353(84.2 \%)$ & $9(56.2 \%)$ & \multirow[t]{2}{*}{8.988} & \multirow[t]{2}{*}{0.011} \\
\hline Bilateral & $10(20.8 \%)$ & $66(15.8 \%)$ & $7(43.8 \%)$ & & \\
\hline \multicolumn{6}{|l|}{ Surgery } \\
\hline Total thyroidectomy & 39 (81.3\%) & $332(79.2 \%)$ & $13(81.3 \%)$ & \multirow[t]{2}{*}{0.138} & \multirow[t]{2}{*}{0.933} \\
\hline Near-total thyroidectomy & $9(18.7 \%)$ & $87(20.8 \%)$ & $3(18.7 \%)$ & & \\
\hline \multicolumn{6}{|l|}{ LNM } \\
\hline Yes & $31(64.6 \%)$ & $180(43.0 \%)$ & $10(62.5 \%)$ & \multirow[t]{2}{*}{9.983} & \multirow[t]{2}{*}{0.007} \\
\hline No & 17 (35.4\%) & 239 (57.0\%) & $6(37.5 \%)$ & & \\
\hline \multicolumn{6}{|l|}{${ }^{131}$ | radiotherapy } \\
\hline Yes & $24(50.0 \%)$ & 163(38.9\%) & $11(68.8 \%)$ & \multirow[t]{2}{*}{7.463} & \multirow[t]{2}{*}{0.024} \\
\hline No & $24(50.0 \%)$ & $256(61.1 \%)$ & $5(31.2 \%)$ & & \\
\hline
\end{tabular}

et al. reported the BRAF V600E mutation rate in Korean PTC patients was $80.8 \%$ [32]. Presently, the prevalence of BRAF V600E mutation of PTC patients was up to $88.2 \%$, even higher than that in Korea. Hence, it is of great significance to obtain more evidence-based support of gene mutation in PTC patients.

Several studies have reported the coexistence of BRAF V600E and TERT gene mutations. However, it is still unclear why TERT promoter mutations most likely occur in cooperation with BRAF V600E mutation. In 2018, Ren $\mathrm{H}$ et al. found $3.5 \%$ PTC patients with co-existence of BRAF V600E and TERT promoter mutations [22]. In 2019, Colombo C et al. demonstrated that the double mutation rate of BRAF V600E and TERT promoter in aggressive PTC was 12\% [33]. In this study, we observed 2.1\% patients with BRAF V600E and TERT double mutations, lower than reported data around the world. Importantly, conflicting results were reported involving the clinical effects of BRAF V600E/TERT coexistence. In 2018, Jin A thought that patients with combined mutations were more likely to have a poor prognosis and outcome [11]. On the contrary, Nasirden A et al. found TERT/BRAF V600E double mutant tumors showed lower disease-free survival rate than BRAF V600E mutant tumors [21]. Presently, our meta-analysis provided strong evidence that BRAF V600E/TERT promoter mutations were significantly correlated with lymph node metastasis, multifocality, distant metastasis, tumor

Table 4 Logistic regression analyses between BRAF V600E mutation group and BRAF V600E wild group

\begin{tabular}{|c|c|c|c|c|c|c|c|}
\hline \multirow[t]{2}{*}{ Index } & \multirow[t]{2}{*}{$\beta$} & \multirow[t]{2}{*}{ SE } & \multirow[t]{2}{*}{ Wals } & \multirow[t]{2}{*}{ Sig. } & \multirow[t]{2}{*}{$\mathrm{HR}$} & \multicolumn{2}{|l|}{$95 \% \mathrm{Cl}$} \\
\hline & & & & & & upper & lower \\
\hline Lymph node metastasis & -2.363 & 0.526 & 20.154 & $<0.001$ & 0.094 & 0.034 & 0.264 \\
\hline${ }^{131}$ | radiotherapy & 2.032 & 0.526 & 14.930 & $<0.001$ & 7.628 & 2.721 & 21.378 \\
\hline $\begin{array}{l}\text { Pathology } \\
\text { (PTC/PTMC) }\end{array}$ & -0.418 & 0.334 & 1.564 & 0.211 & 0.659 & 0.342 & 1.267 \\
\hline
\end{tabular}


Table 5 Logistic regression analyses between BRAF V600E mutation alone and double mutant group

\begin{tabular}{|c|c|c|c|c|c|c|c|}
\hline \multirow[t]{2}{*}{ Index } & \multirow[t]{2}{*}{$\beta$} & \multirow[t]{2}{*}{ SE } & \multirow[t]{2}{*}{ Wals } & \multirow[t]{2}{*}{ Sig. } & \multirow[t]{2}{*}{$H R$} & \multicolumn{2}{|l|}{$95 \% \mathrm{Cl}$} \\
\hline & & & & & & upper & lower \\
\hline Age & 0.126 & 0.031 & 17.008 & $<0.001$ & 1.135 & 1.069 & 1.205 \\
\hline Location of leision (bilateral/unilateral) & 0.616 & 0.710 & 0.754 & 0.385 & 1.852 & 0.461 & 7.443 \\
\hline Number of leision (multiple/single) & 1.418 & 0.710 & 3.983 & 0.046 & 4.128 & 1.026 & 16.614 \\
\hline Lymph node metastasis & -0.711 & 1.427 & 0.248 & 0.619 & 0.491 & 0.030 & 8.058 \\
\hline${ }^{131}$ | radiotherapy & 0.840 & 1.487 & 0.319 & 0.572 & 2.315 & 0.126 & 42.70 \\
\hline Pathology (PTC/PTMC) & 1.375 & 0.594 & 5.365 & 0.021 & 3.954 & 1.235 & 12.654 \\
\hline
\end{tabular}

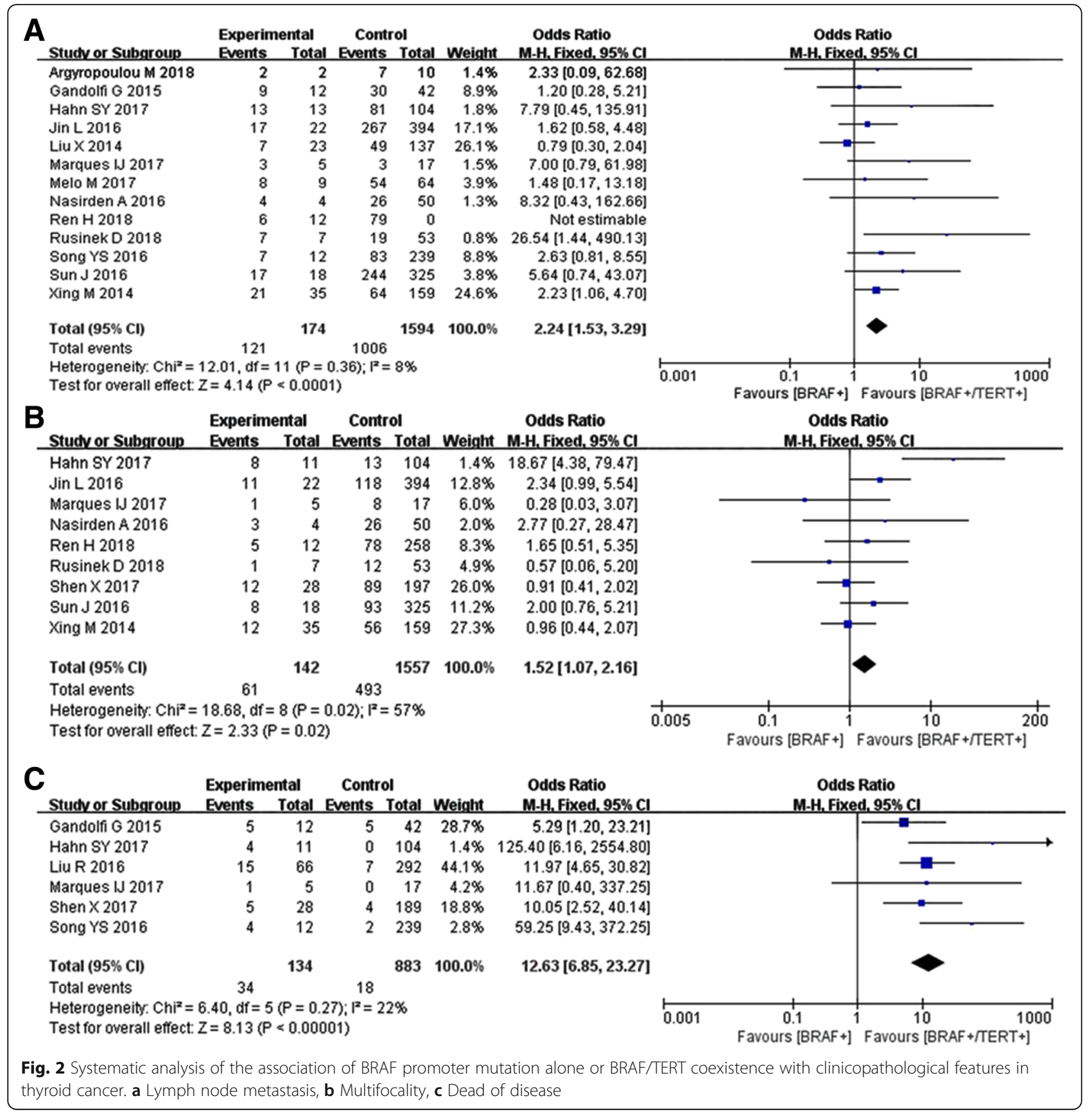




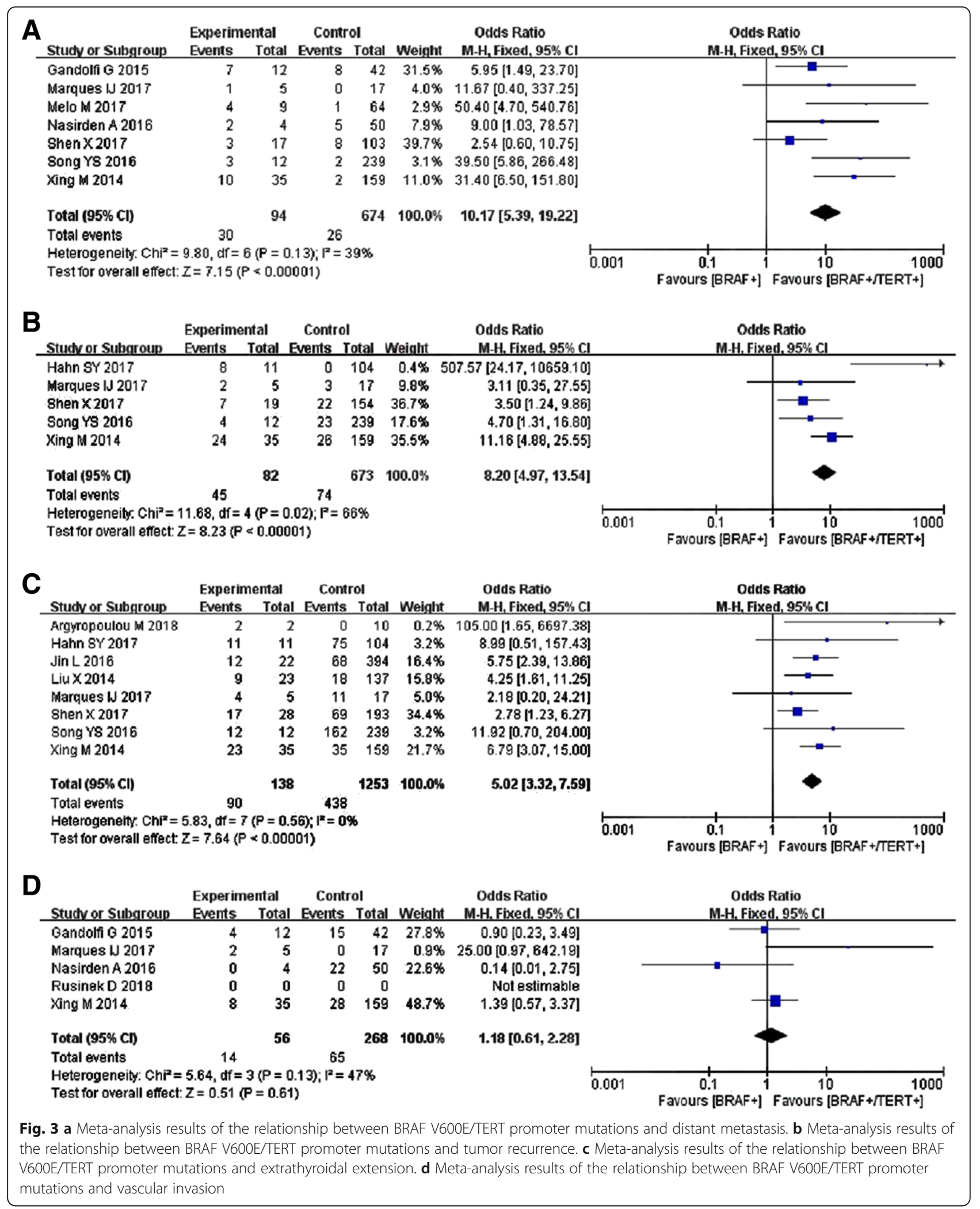


recurrence, extrathyroidal extension, and dead of disease. The meta-analysis by Vuong HG et al. achieved the same results. The combination of BRAF V600E and TERT promoter mutations could classify PTCs into four distinct risk groups with decreasing aggressiveness as follows: coexisting BRAF V600E and TERT > BRAF V600E alone $>$ no mutations [13].

There are limited studies about NRAS gene mutation in PTC, still less about BRAF V600E and NRAS gene co-mutation. In 2017, Melo $\mathrm{M}$ et al. reported $1.2 \% \mathrm{mu}-$ tation frequency of NRAS in primary PTCs [20]. Tobiás $\mathrm{B}$ et al. found $3.1 \%$ NRAS mutation in Hungarian Patients with PTC [34]. In 2018, NRAS promoter mutations were identified in 2 PTC cases, with a prevalence of $3.4 \%$ in the Greek Population [9]. In this study, the prevalence of NRAS mutation was $1.2 \%$. NRAS promoter mutation was also likely to coexist with BRAF V600E mutation in PTC. However, the limited number of NRAS mutation interfered the research of its clinicopathological relationship. Because of the small number of NRAS mutation, we could not perform the clinicopathological relationship analysis. With the enlargement of mutant participants, we could obtain more promising evidence in the near future.

In conclusion, prevalence of BRAF V600E mutation in Northwest China was higher than other areas. Age, lymph node metastasis, and ${ }^{131}$ I radiotherapy were risk factors for BRAF V600E mutation. Age, multiple lesions, and pathology were independent factors for combination mutations. Coexistence of BRAF V600E and TERT promoter mutations were significantly correlated with lymph node metastasis, multifocality, distant metastasis, tumor recurrence, extrathyroidal extension, and dead of disease. The predictive value of NRAS combinational mutation with BRAF V600E needs more evidence.

\section{Abbreviations}

FFPE: Formalin-fixed and paraffin-embedded; PCR: Polymerase chain reaction; PTC: Papillary thyroid cancer; TERT: Telomerase reverse transcriptase

\section{Acknowledgments}

We thanks the clinical pathologist from pathology department in Xijing Hospital.

\section{Authors' contributions}

TW and RL designed the protocol and supervised the progress. JX collected the clinical information of participants. $\mathrm{MH}$ and $\mathrm{CY}$ analyzed the patient data and write the manuscript. All authors read and approved the final manuscript.

\section{Funding}

This work was supported by the National Science Foundation of China (No. 81572917).

\section{Availability of data and materials \\ Yes}

\section{Ethics approval and consent to participate}

Ethical approval for the study was provided by the Ethical Committees of Xijing Hospital.
Consent for publication

Not applicable.

\section{Competing interests}

The authors declare that they have no competing interests.

Received: 6 March 2019 Accepted: 20 June 2019

Published online: 12 July 2019

\section{References}

1. Siegel RL, Miller KD, Jemal A. Cancer statistics, 2019. CA Cancer J Clin. 2019; 69:7-34.

2. Roman BR, Morris LG, Davies L. The thyroid cancer epidemic, 2017 perspective. Curr Opin Endocrinol Diabetes Obes. 2017;24:332-36.

3. Li DD, Zhang YF, Xu HX, et al. The role of BRAF in the pathogenesis of thyroid carcinoma. Front Biosci (Landmark Ed). 2015;20:1068-78.

4. Liu R, Xing M. TERT promoter mutations in thyroid cancer. Endocr Relat Cancer. 2016;23:R143-55

5. Xing M. Molecular pathogenesis and mechanisms of thyroid cancer. Nat Rev Cancer. 2013:13:184-99.

6. Jang EK, Song DE, Sim SY, et al. NRAS codon 61 mutation is associated with distant metastasis in patients with follicular thyroid carcinoma. Thyroid. 2014;24:1275-81

7. Mond M, Alexiadis M, Fuller PJ, et al. Mutation profile of differentiated thyroid tumours in an Australian urban population. Intern Med J. 2014;44: 727-34.

8. Qasem E, Murugan AK, Al-Hindi H, et al. TERT promoter mutations in thyroid cancer: a report from a Middle Eastern population. Endocr Relat Cancer. 2015:22:901-8

9. Argyropoulou M, Veskoukis AS, Karanatsiou PM, et al. Low Prevalence of TERT Promoter, BRAF and RAS Mutations in Papillary Thyroid Cancer in the Greek Population. 2018.

10. Liang J, Cai W, Feng D, et al. Genetic landscape of papillary thyroid carcinoma in the Chinese population. 2018;244:215-26.

11. Jin $\mathrm{A}, \mathrm{Xu} \mathrm{J}$, Wang $\mathrm{Y}$. The role of TERT promoter mutations in postoperative and preoperative diagnosis and prognosis in thyroid cancer. Medicine (Baltimore). 2018;97:e11548.

12. Sun J, Zhang J, Lu J, et al. BRAF V600E and TERT Promoter Mutations in Papillary Thyroid Carcinoma in Chinese Patients. PLoS One. 2016;11:e0153319.

13. Vuong HG, Altibi AMA Prognostic implication of BRAF and TERT promoter mutation combination in papillary thyroid carcinoma-A meta-analysis. 2017; 87:411-17

14. Gandolfi G, Ragazzi M, Frasoldati A, et al. TERT promoter mutations are associated with distant metastases in papillary thyroid carcinoma. Eur J Endocrinol. 2015;172:403-13.

15. Hahn SY, Kim TH, Ki CS, et al. Ultrasound and clinicopathological features of papillary thyroid carcinomas with BRAF and TERT promoter mutations. Oncotarget. 2017:8:108946-57.

16. Jin L, Chen E, Dong S, et al. BRAF and TERT promoter mutations in the aggressiveness of papillary thyroid carcinoma: a study of 653 patients. Oncotarget. 2016;7:18346-55.

17. Liu R, Bishop J, Zhu G, et al. Mortality Risk Stratification by Combining BRAF V600E and TERT Promoter Mutations in Papillary Thyroid Cancer: Genetic Duet of BRAF and TERT Promoter Mutations in Thyroid Cancer Mortality. JAMA Oncol. 2016;2:202-8.

18. Liu X, Qu S, Liu R, et al. TERT promoter mutations and their association with BRAF V600E mutation and aggressive clinicopathological characteristics of thyroid cancer. J Clin Endocrinol Metab. 2014;99:E1130-6.

19. Marques IJ, Moura MM, Cabrera R, et al. Identification of somatic TERT promoter mutations in familial nonmedullary thyroid carcinomas. 2017;87: 394-99.

20. Melo M, Gaspar da Rocha A, Batista R, et al. TERT, BRAF, and NRAS in Primary Thyroid Cancer and Metastatic Disease. J Clin Endocrinol Metab. 2017;102:1898-907.

21. Nasirden A, Saito T, Fukumura Y, et al. In Japanese patients with papillary thyroid carcinoma, TERT promoter mutation is associated with poor prognosis, in contrast to BRAF (V600E) mutation. Virchows Arch. 2016;469:687-96.

22. Ren $H$, Shen $Y$, Hu D, et al. Co-existence of BRAF(V600E) and TERT promoter mutations in papillary thyroid carcinoma is associated with tumor aggressiveness, but not with lymph node metastasis. Cancer Manag Res. 2018;10:1005-13. 
23. Rusinek D, Pfeifer A, Krajewska J, et al. Coexistence of TERT Promoter Mutations and the BRAF V600E Alteration and Its Impact on Histopathological Features of Papillary Thyroid Carcinoma in a Selected Series of Polish Patients. Int J Mol Sci. 2018;19.

24. Shen X, Liu R, Xing M. A six-genotype genetic prognostic model for papillary thyroid cancer. Endocr Relat Cancer. 2017;24:41-52.

25. Song YS, Lim JA, Choi H, et al. Prognostic effects of TERT promoter mutations are enhanced by coexistence with BRAF or RAS mutations and strengthen the risk prediction by the ATA or TNM staging system in differentiated thyroid cancer patients. Cancer. 2016;122:1370-9.

26. Xing M, Liu R, Liu X, et al. BRAF V600E and TERT promoter mutations cooperatively identify the most aggressive papillary thyroid cancer with highest recurrence. J Clin Oncol. 2014;32:2718-26.

27. Fagin JA, Wells SA. Biologic and Clinical Perspectives on Thyroid Cancer. N Engl J Med. 2016:375:1054-67.

28. Poller DN, Glaysher S. Molecular pathology and thyroid FNA. Cytopathology. 2017;28:475-81.

29. Yip L, Nikiforova MN, Yoo JY, et al. Tumor genotype determines phenotype and disease-related outcomes in thyroid cancer: a study of 1510 patients. Ann Surg. 2015;262:519-25; discussion 24-5.

30. Fraser $\mathrm{S}$, Go C, Aniss A, et al. BRAF(V600E) Mutation is Associated with Decreased Disease-Free Survival in Papillary Thyroid Cancer. World I Surg. 2016;40:1618-24.

31. Ilera V, Dourisboure R, Colobraro A, et al. BRAF V600E mutation in thyroid nodules in Argentina. Medicina (B Aires). 2016;76:223-9.

32. Lee SE, Hwang TS, Choi YL, et al. Molecular Profiling of Papillary Thyroid Carcinoma in Korea with a High Prevalence of BRAF(V600E) Mutation. Thyroid. 2017;27:802-10.

33. Colombo C, Muzza M, Proverbio MC, et al. Impact of Mutation Density and Heterogeneity on Papillary Thyroid Cancer Clinical Features and Remission Probability. Thyroid. 2019;2:237-51.

34. Tobias B, Halaszlaki C, Balla B, et al. Genetic Alterations in Hungarian Patients with Papillary Thyroid Cancer. Pathol Oncol Res. 2016;22:27-33.

\section{Publisher's Note}

Springer Nature remains neutral with regard to jurisdictional claims in published maps and institutional affiliations.

Ready to submit your research? Choose BMC and benefit from:

- fast, convenient online submission

- thorough peer review by experienced researchers in your field

- rapid publication on acceptance

- support for research data, including large and complex data types

- gold Open Access which fosters wider collaboration and increased citations

- maximum visibility for your research: over $100 \mathrm{M}$ website views per year

At $\mathrm{BMC}$, research is always in progress.

Learn more biomedcentral.com/submissions 